\title{
Development of the System of Preparing Electronic Reports on University Scientific and Research Activities at Orel State University
}

\section{Viktoria Dorofeyeva}

Faculty of Physics and Mathematics, Orel State University, Komsomolskaya Str., 95 Orel, 302026, Russia; Email: dorofeevavi@gmail.com

\begin{abstract}
Elena Dudina
Bureau of research and innovation, Orel State University, Komsomolskaya Str., 95 Orel, 302026, Russia; Email: I.dudina-n@yandex.ru

\section{Dmitry Nikolskiy}

Faculty of Physics and Mathematics, Orel State University, Komsomolskaya Str., 95 Orel, 302026, Russia; Email: nikolskydni@gmail.com

Yuriy Fedyaev

Faculty of Physics and Mathematics, Orel State University, Komsomolskaya Str., 95 Orel, 302026, Russia; Email: fedyaevys@gmail.com

\section{Elena Hovanskaya}

Department of innovation activity, faculty of Philology, Orel State University, Komsomolskaya Str., 95 Orel, 302026, Russia; Email: I.hovanskaja@yandex.ru
\end{abstract}

\author{
Doi:10.5901/mjss.2015.v6n6s5p16
}

\section{Abstract}

The paper gives a ground for the relevance of the development of the system of preparing electronic reports on the scientific research carried out at Orel state University. The specific features of the system are analyzed in the context of the organization of university research activities. To design a system, various information technologies should be used to create the software product that is in line with the modern trends of using web technologies in applications. As a result, the structure of the information and analytical system for the preparation of individual forms of electronic reporting was developed in the context of the organization of university research activities and the software was implemented in a modern programming language. After the testing of applications the system is recommended for introduction at all departments of Orel state University. At the next step it is planned to simulate and implement the system components for preparation of integrated forms of electronic reporting on scientific activity of the university departments, as well as for the preparation of consolidated forms of electronic reporting of scientific research activities of the university on the whole.

Keywords: scientific research, information analysis system, Web-application

\section{Introduction}

Collecting comprehensive information on the scientific research carried out at the university is one of the pressing problems in the wide range of university activities. The scientific research ranges high in the methodology of calculation of indicators for monitoring the effectiveness of educational institutions of higher education. This entails the increase of requirements for the university academic staff in terms of revitalization of scientific activity (Puzankova et. al., 2014).

The scientific research is carried out in accordance with the plans for scientific research projects (SRP) completed within the programmes and grants of the Ministry of Education and Science of the Russian Federation (Minobrnauki of Russia), Russian Science Foundation (RSF), Russian Foundation of Fundamental Research (RFFR), Russian Foundation for Humanities (RFH), Federal Target Programmes (FTP) and the plans of Research and Development 
(R\&D) completed according to economic contracts with agricultural and scientific institutions.

The structure of the University scientific research sector includes the department of scientific research and innovations; department of innovation activity; department of intellectual property, patents and inventions; the department for training of highly qualified academic staff; the Scientific and Technical Council; research institutes; scientific research centers; laboratories; museums and other scientific departments. Each major research department has its own hierarchy (Belousov et. al., 2014).

Each scientific research department drafts plans of research activities for an upcoming calendar year. At the end of the year it reports on its progress and performance. Apart from that, each academic staff member fills out an individual research plan and later reports on its implementation orally or in writing at the department meeting.

This article presents the results of a single phase of the analysis of the scientific research carried out at Orel state university and the development of the information analytical system which is planned to be used at Orel State University.

The main goal of this practical work is to elaborate a system that will be an effective tool for the administrative and management personnel and to help evaluate the scientific research sector of the university as a whole and in each of its structural unit in particular. Such analysis is the basis for making effective management decisions at all levels (Egghe, 2012; Glänzel, 2012, Hirsch, 2010; Nederhof et. al., 2009, Mauleón and Bordons, 2009).

By the time we began to design the plan, all the planned and reporting activities were performed on paper and various forms and tables developed by the Scientific and Technical Council were still in use. This caused considerable inconvenience, since modern information technology which enables processing of large amounts of information was almost never used (Mauleón et. al. 2012; Bordons et. al., 1999; Rinia et. al., 2002; Van Leeuwen, 2008).

The main reason for developing the system was to create a tool that would help to efficiently collect and analyze data, both personal and generalized across individual research teams and organizations, in order to obtain reliable indicators of performance and focus of the scientific research (Tijssen and Leeuwen, 2006; Starodubov et. al., 2012; Kotsemir, 2012).

Major outcomes of the scientific research conducted by any organization generally take the form of publications, results of patent research, participation in conferences, supervising students writing course papers, degree works and theses, etc. In this case, only academic staff members' annual reports presented with varying degrees of detail can serve as a source of such information. This means that indeed there is a pressing need for automation of the analysis of this activity results due to the significant increase in the number of participants. On the other hand, without a well-organized system for preparing an electronic reporting framework for the results of scientific research, it will obviously be impossible to process the accumulated amount of information.

It is suggested that the results of the work carried out by individual staff members as well as each department on the whole should be used as the source data. The latter include information about scientific findings, publications, textbooks and manuals, certificates and patents, conference papers, diplomas and dissertations supervision, and other types of scientific activity. Management of this information involves its collection, registration and systematization, storage, analysis and delivery on request.

Thus, we have identified the main objectives of the system which include providing an academic staff of each university department with an opportunity to plan and register the results of their scientific research in an automatic mode and enabling the heads of individual departments and the whole organization to carry out a quantitative and qualitative analysis of the research activities of each staff member, individual department and the entire organization (Puzankova et. al., 2014).

In order to achieve these objectives, at the first stage of the system development it was decided to perform an automated filling out of individual reporting forms. Due to the increased number of indicators characterizing research activities, there was a significant complication of individual plans and reports (Dorofeeva et. al., 2014).

For a more effective solution we carried out a comparative analysis of the information systems presented on the Internet which are used to tackle such problems. At present there is a large number of automated accounting systems which were created to efficiently analyze research, innovation and education activities and became widely used with the development of the Internet and web-based data processing.

One class of such systems is represented by Major Web services that are being developed in the framework of projects such as Web of Science, Scopus, Google Scholar, the Russian portal eLibrary.ru and the like. Basically, these systems are bibliographic and abstract databases. In varying degrees they combine such functions as indexing and retrieval of scientific papers. Foreign projects that use semantic technologies belong to the second class of the systems of scientific information analysis. It is important to mention such systems as Bibster, JeromeDL, Flink, AIR, as well as the semantic database of general purpose, such as Cyc, YAGO, True Knowledge, Freebase, DBpedia and Wikitology. The third group includes Russian projects, for example, the Integrated System of Information Resources (ISIR) developed by 
the Russian Academy of Sciences, the complex designed by the Institute of Informatics Systems of the Siberian Branch of the Russian Academy of Sciences (IIS SB RAS), the "Istina" system which is being implemented at Moscow State University named after M. V. Lomonosov, as well as the system "Pure" by Elsevier (Afonin et al., 2014).

In most situations these systems have obvious advantages, however, it was concluded that they could not be used in this particular case. Primarily, this is due to the way a scientific research is carried out in various scientific organizations and the complex long-term adaptation to the particular situation (the complexity of data input, the difficulty of searching for information, the use of "hard" classification schemes and data circuits, etc.), as well the high cost of information systems on the market.

In order to design and develop a suitable electronic reporting system a special research team consisting of professors of physics and mathematics and the scientific department staff was created at Orel State University. We had to design a system that would ensure the collection of reliable information from each staff member engaged in research and that would at the same time allow us to process this information in order to produce a variety of reports both at individual departments and at the university on the whole.

The following technical system requirements can be used: completeness of data; the dynamics of the knowledge base structure; minimization of the time for data processing; data integrity (which lies in the authenticity and accuracy of information, its security against possible unintended or malicious distortion); confidentiality (access to the applications of the system should be allowed only to people entitled to it); security (which is based on a developed system of usernames and passwords); multi-user access with differentiation of access rights; a user-friendly and intuitive interface designed for users with varying degrees of training; integration into a single information space of the university (Antopol'skii, 2015; Moskovkin, 2013; Vasilenko et al., 2014).

\section{Objective, Methodology and Research Design}

Current research corresponds to high priority scientific areas, technology and engineering in the Russian Federation (information and telecommunication systems), as well as priority areas of modernization and technological development of the Russian economy (strategic information technologies, including the development of supercomputers and software) and critical technologies (technologies of processing, storage, transmission and protection of information).

The methodological basis of the research was made up of the systemic approach elements which contribute to the development of an effective research strategy of information systems in their interconnection and interdependence and of the Information Security Doctrine of the Russian Federation.

To achieve the stated objectives we used a set of research methods varying:

- according to the degree of the design automation - the method of computer-aided design that carries out generation or configuration (setting) of design solutions on the basis of the use of special software tools;

- according to the degree of the use of standard design solutions - the method of original (individual) design in which any design solutions are developed "from scratch" in accordance with the requirements of the information system;

- $\quad$ according to the degree of adaptability of the design decisions - the parameterization method in which design decisions are adjusted in accordance with variable parameters.

To design a system, various information technologies should be used to create a software product that is in line with the modern trends of using web technologies in applications and that corresponds to the state and prospects of developing a scientific and technical complex in the country. This will help to make available the service that is provided by an application developed in any place that has the Internet connection.

Among major challenges that the team of the system developers faces are the following: the analysis of the forms and types of reporting on the scientific research carried out at the university; the development and modeling of the database and the interconnections between its objects for the information system; the development of screen forms with ergonomic interface requirements; the development of the software code of form handlers; the development of the serverside code of the information system. A designed software application should take into account all the modern requirements to software products of this class and should be created on the basis of modern technology.

While discussing the objectives of the project, we decided to create a system with a client-server architecture based on web technologies (Graph 1). The development of the Web applications is carried out on the basis of the Django framework in Python. Django is a third generation Web framework and is designed to create dynamic sites quickly (Kaplan-Moss and Holovaty, 2014) The Gunicorn server is used as a primary web server. The project database management system MySQL is chosen for handling the database of the project. The Web application functions on a special server operated by the Linux system. A customer response generated by the server is generally a HTML- 
document. To create the user interface of web application the framework of Semantic UI is applied. The behavior of the elements from the client-side is defined using the JavaScript-library jQuery. The applied software is free and highly reliable.

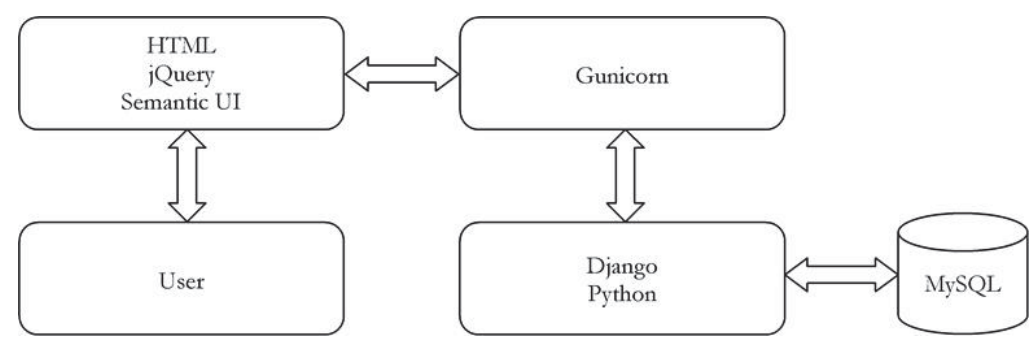

Graph 1. Project architecture

Source: Own analysis, http://nir.univ-orel.ru/

The Web framework Django implements the "Model-View-Controller" design pattern, MVC. The Django toolkit includes the object-relational mapping (ORM) which allows automatic generation of SQL-based queries on the basis of the Python-code. The framework of Django also includes a built-in template language and supports configuration of URLaddresses. The MVC design pattern makes it possible to split into separate components the model of the application data, the user interface (view) and the connection between the user and the application (behavior/controller). This separation allows to increase the code reusability and to make its modification easier. Linking the project to the Python makes it possible to use a rich set of other language libraries that implement various functions. It should also be noted that in the framework of Django a complete administrator Web-based interface is automatically generated on the basis of patterns predefined by the programmer. Using it, the administrator can view, add, modify or delete any information in the database.

\section{Research Outcomes and Discussion}

The project is meant to be carried out in three annual steps. At the first stage (2014) the system components were modeled and implemented for the preparation of individual forms of electronic reporting on scientific research. At the second phase (2015) modeling and implementation of system components for integrated forms of electronic reporting on the scientific activity of structural subdivisions of the university will be carried out. At the third stage (2016) system components for the preparation of consolidated forms of electronic reporting on the scientific activities of the university on the whole will be modeled and implemented. Each stage involves preparing a guide to using the information-analytical system components.

The first stage of the Web application development resulted in the planning system of scientific research activities for each structural subdivision of the university (department, research laboratory). Each staff member logs in the system using the web interface. To do this, they fill in an electronic form which contains the following entries: Username, Password, E-mail, Name, Patronymic name. They should also put a check mark in the checkbox box marked "I agree to the processing of my personal data". After this, users must confirm their registration by clicking a special link in the email that comes to their e-mail. Then they should be authorized on the main page of the web application. After this users enter their personal cabinet where the following services become available: Profile, Plan, Report.

The profile contains the following menu entries: Account, Personal data, Title. The Account section gives an opportunity to change the login, password and e-mail. The Personal data entry allows one to edit the name, first name and patronymic name. It is also important to specify one's degree and academic rank here. Users can enter the area of science which awarded them the academic degree and the department or specialty for which they were awarded the academic title. In the Position section one should select out of the tree list a structural unit of the university and specify the position of the rate at which one works. The user can have several titles, each of them has a sign of Status. This attribute can take on two values: Confirmed or Not confirmed. If the title is confirmed, the data entered is recorded in the respective structural unit. Titles must be confirmed by the head of the department.

Planning research activities by each academic staff member involves filling in the following forms: Scientific research, Grant activities, Participation in events, Student research management and supervision, Results of intellectual 
activity, Scientific schools. Each form allows adding, editing and saving the data. The first two forms will now be examined in more detail.

When filling out the form Scientific research each lecturer chooses a department, one of the project topics registered in the database of the university and the kind of their involvement: Manager (M), Performer $(P)$, Support staff (S). Then they should enter the purpose and expected outcomes of the research activity. For each topic of research activities, the following indicators should be filled in:

$>$ Total number of papers (apart from conference abstracts), total, including articles published in foreign journals.

$>$ Total number of papers published in indexed scientific journals, total, including articles published in:

- scientific journals included in Higher Attestation Commission database;

- Russian Science Citation Index (RSCI) database;

- Web of Science;

- Scopus;

- European Reference Index for the Humanities and Social Sciences (ERIH PLUS);

- other international information analysis systems.

$>$ Number of monographs, total, including monographs:

- published abroad;

- co-authored by foreign writers.

$>$ Number of course books, total, including course books:

- classified and recommended by the Academic Methdological Association (AMA);

- classified and recommended by Minobrnauki of Russia;

- other classifications.

$>$ Number of study guides / instruction manuals, total, including study guides / instruction manuals:

- classified and recommended by the Academic Methdological Association (AMA);

- classified and recommended by Minobrnauki of Russia;

- other classifications.

All entered information is stored in the database. This allows automatic generation of plans for scientific research activities of any structural unit of the university. Table 1 shows an example of consolidated data for one of the departments. Table 2 shows a fragment of the research activities scheduled for department topics.

Table 1. Consolidated data for department scientific research activities

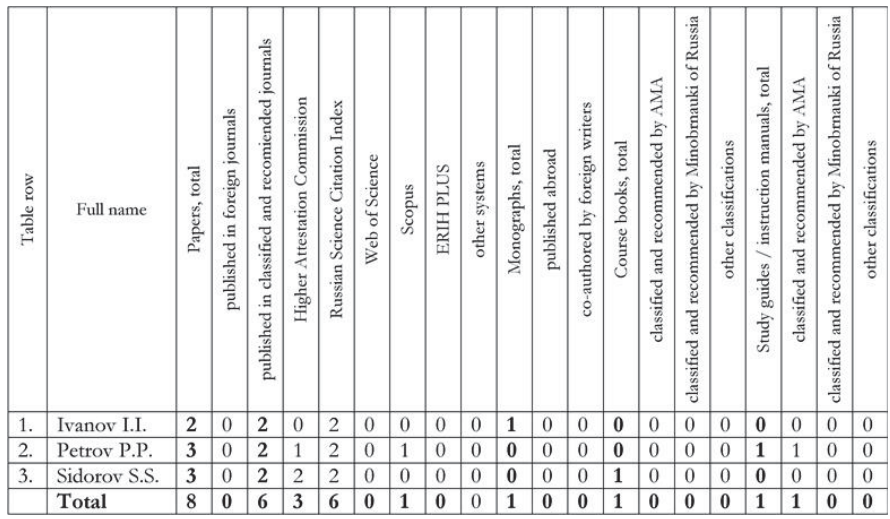

Source: Own analysis 
Table 2. Scientific research activities on one of department topics

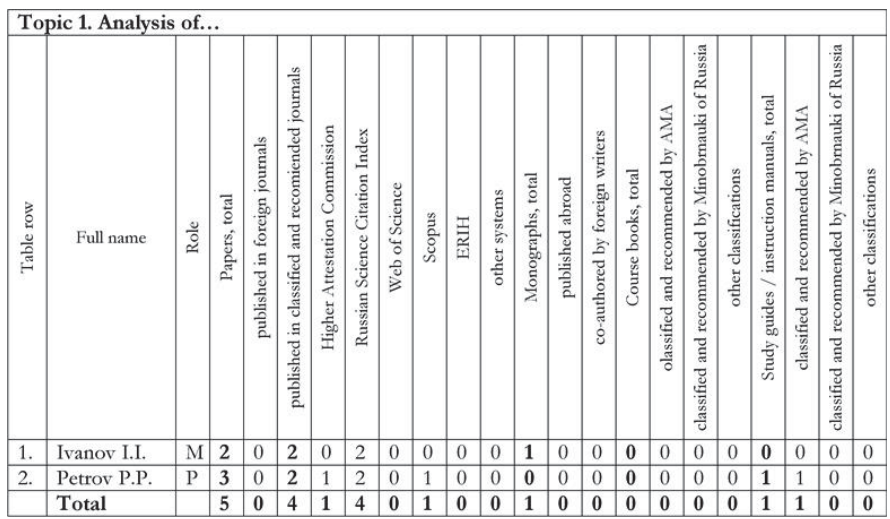

Source: Own analysis

The grant activity form contains two sections: 1) intended applications; 2) ongoing projects. In the planned projects section a staff member chooses the department and indicates the number of applications $(\Sigma)$ in the following areas:

$>$ Russian Research Fund;

$>$ Russian Foundation for Basic Research;

$>$ Russian Humanitarian Science Foundation;

$>$ The Federal target program;

$>$ Government order, Minobrnauki of Russia (basic part);

$>$ Government order, Minobrnauki of Russia (project part);

$>$ Economic agreement.

The number of applications where a staff member acts as a manager $(\mathrm{M})$ is also indicated here. This allows to control a total number of applications from each structural unit. If one plans to apply for grants in other areas, one can mention it a special text box.

In the ongoing projects section staff members select a project registered in the University database and specifies the form of their participation (manager, performer, support staff). Table 3 shows a summary of the planned applications for one of the departments.

Other forms were filled out in a similar way. The described system allows one to generate automatically a research plan for a structural unit of the university and monitor the effectiveness of the corresponding subdivision. In the future, the developed web-based application will solve the problem of automating the preparation of electronic reporting on the scientific research carried out at the university and optimize the process of obtaining and processing information.

Table 3. Intended applications for grants

\begin{tabular}{|c|c|c|c|c|c|c|c|c|c|c|c|c|c|c|c|}
\hline \multirow{2}{*}{ 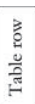 } & \multirow[t]{2}{*}{ Full name } & \multicolumn{2}{|c|}{ RSF } & \multicolumn{2}{|c|}{ RFBR } & \multicolumn{2}{|c|}{ RHSF } & \multicolumn{2}{|c|}{ FTP } & \multicolumn{2}{|c|}{$\begin{array}{l}\text { Government } \\
\text { order (basic } \\
\text { part) }\end{array}$} & \multicolumn{2}{|c|}{$\begin{array}{c}\text { Government } \\
\text { order (project } \\
\text { part) }\end{array}$} & \multicolumn{2}{|c|}{$\begin{array}{l}\text { Economic } \\
\text { agreement }\end{array}$} \\
\hline & & $\Sigma$ & $\mathrm{M}$ & $\Sigma$ & $\mathrm{M}$ & $\Sigma$ & $\mathrm{M}$ & $\Sigma$ & M & $\Sigma$ & $\mathrm{M}$ & $\Sigma$ & $\mathrm{M}$ & $\Sigma$ & $\mathrm{M}$ \\
\hline 1. & Ivanov I.I. & 0 & 0 & 2 & 1 & 1 & 1 & 0 & 0 & 0 & 0 & 0 & 0 & 0 & 0 \\
\hline 2. & Petrov P.P. & 1 & 1 & 0 & 0 & 0 & 0 & 0 & 1 & 1 & 1 & 0 & 0 & 0 & 0 \\
\hline 3. & Sidorov S.S. & 0 & 0 & 0 & 0 & 1 & 0 & 1 & 0 & 0 & 0 & 1 & 1 & 0 & 0 \\
\hline & Total & 1 & 1 & 2 & 1 & 2 & 1 & 1 & 1 & 1 & 1 & 1 & 1 & 0 & 0 \\
\hline
\end{tabular}

Source: Own analysis

The developed system components have been tested at a number of Orel State University departments (Physics and Mathematics, Philosophy, Documentation and Teacher education, Medical Institute). The work of the Web application in a test mode has identified some deficiencies of the system related primarily to the different levels of teachers' experience of working with modern information technologies. This made it necessary to provide the academic staff with assistance and 
organize workshops focused on the stages of work with individual research plans. The testing results of the system were discussed at the meetings of the Scientific Council at OSU, the Scientific and Technical Council and approved by OSU. The system is recommended for introduction at all departments of the University. It should be noted that certain elements of the system can be used in the educational process within the disciplines taught at Faculty of Mathematics and Physics, Faculty of Documentation and Teacher Education.

\section{Conclusion}

As part of the research work the following objectives were achieved:

- a model of the components of the system for the preparation of individual forms of reporting on scientific activity was created;

- the software implementation of the system components designed for the preparation of individual forms of reporting on research was completed.

The following scientific and technical results were obtained:

- the structure of the information and analytical system for the preparation of individual forms of electronic reporting was developed in the context of the organization of university research activities;

- the software was implemented in a modern programming language;

- the testing of the applications was performed.

Thus, the new preparation system of the individual forms of electronic reporting on the scientific research carried out by the members of Orel State University staff was created. The system meets the modern trends of using web technologies in applications. At the next step it is planned to simulate and implement the system components for preparation of integrated forms of electronic reporting on scientific activity of the university departments, as well as for the preparation of consolidated forms of electronic reporting of scientific research activities of the university on the whole.

\section{Acknowledgements}

The paper was prepared as part of the State order of the Ministry of Education and Science of the Russian Federation for the Federal State Government-financed Educational Institution of Higher Professional Education "Orel State University" in 2015, project \# 1379.

\section{References}

Afonin, S.A. et al. Intellektual'naja sistema tematicheskogo issledovanija nauchno-tehnicheskoj informacii (ISTINA) [Intelligent system for a case study of scientific and technical information. (Truth)]. Moskva: Izdatel'stvo Moskovskogo gosudarstvennogo universiteta. Moscow: Moscow University Publishing House, 2014.

Antopol'skii, A. B. (2015). Algorithms and methods that measure the level of development of information resources at scientific and educational organizations. Scientific and Technical Information Processing, 42(1), 13-23. http://doi.org/10.3103/S0147688215 010025

Belousov, K. I., Baranov, D. A., \& Zelyanskaya, N. L. (2014). A research team and its subject area: Towards the question of the effective planning of scientific activities. Scientific and Technical Information Processing, 41(2), 85-97. http://doi.org/10.3103/S01476882 14020026

Bordons, M., Zulueta, M. A., Romero, F., \& Barrigón, S. (1999). Measuring interdisciplinary collaboration within a university: The effects of the multidisciplinary research programme. Scientometrics,46(3), 383-398. http://doi.org/10.1007/BF02459599

Dorofeeva, V. I., Nikolskiy, D. N., \& Fedyaev, Y. S. Razrabotka sistemy jelektronnoj otchetnosti o nauchno-issledovatel'skoj rabote sotrudnikov vuza [Development of a system of electronic reporting on the research work of the university staff]. Pedagogicheskaja informatika, (3), 50-58, 2014.

Egghe, L. (2012). On the correction of the h-index for career length.Scientometrics, 96(2), 563-571. http://doi.org/10.1007/s11192-0120926-Z

Glänzel, W. (2012). The role of core documents in bibliometric network analysis and their relation with h-type indices. Scientometrics, 93 (1), 113-123. http/doi.org/10.1007/s11192-012-0639-3:/

Hirsch, J. E. (2010). An index to quantify an individual's scientific research output that takes into account the effect of multiple coauthorship.Scientometrics, 85(3), 741-754. http://doi.org/10.1007/s11192-010-0193-9

Kaplan-Moss, J., \& Holovaty, A. (2014) The Definitive Guide to Django: Web Development Done Right. (3 edition). Berkeley: Apress.

Kotsemir, M. N. (2012). Dynamics of Russian and World Science Through the Prism of International Publications. Foresight-Russia, 6(1), 38-58.

Mauleón, E., \& Bordons, M. (2009). Male and female involvement in patenting activity in Spain. Scientometrics, 83(3), 605-621. 
http://doi.org/10.1007/s11192-009-0131-x

Mauleón, E., Hillán, L., Moreno, L., Gómez, I., \& Bordons, M. (2012). Assessing gender balance among journal authors and editorial board members. Scientometrics, 95(1), 87-114. http://doi.org/10.1007/s11192-012-0824-4

Moskovkin, V. M. (2013). The construction of academic publishing and terminological structures using the Google Scholar search engine: An example of environmental terms in publications at the classical universities of Kharkiv and Skopje. Scientific and Technical Information Processing, 40(1), 11-16. http://doi.org/10.3103/S0147688213010024

Nederhof, A. J., van Leeuwen, T. N., \& van Raan, A. F. J. (2009). Highly cited non-journal publications in political science, economics and psychology: a first exploration. Scientometrics, 83(2), 363-374. http://doi.org/10.1007/s11192-009-0086-y

Puzankova, E.N., Dudina, E.F., Hovanskaya, E.A., Soboleva, M.A., \& Trishkin A.V. (2014) Scientific and research activities: evaluation criteria, development prospects (based on the activities of the Federal State Government-financed Educational Institution of Higher Professional Education "Orel State University"). Life Science Journal, 11 (11), 658-663.

Rinia, E. J., van Leeuwen, T. N., Bruins, E. E. W., van Vuren, H. G., \& van Raan, A. F. J. (2002). Measuring knowledge transfer between fields of science. Scientometrics, 54(3), 347-362. http://doi.org/10.1023/A:1016078331752

Starodubov, V. I., Kurakova, N. G., Tsvetkova, L. A., Aref'ev, P. G., \& Kurakov, A. F. (2012). The problems associated with the evaluation of world-class competitiveness of Russia's science, as illustrated by clinical medicine. Scientific and Technical Information Processing, 39(3), 139-152. http://doi.org/10.3103/S0147688212030069

Tijssen, R. J. W., \& Leeuwen, T. N. V. (2006). Measuring impacts of academic science on industrial research: A citation-based approach. Scientometrics, 66(1), 55-69. http://doi.org/10.1007/s11192-006-0005-4

Van Leeuwen, T. N. (2008). Strength and weakness of national science systems: A bibliometric analysis through cooperation patterns. Scientometrics, 79(2), 389-408. http://doi.org/10.1007/s11192-009-0426-y

Vasilenko, E. A., Panfilov, V. I., Zhukov, D. Y., \& Sivukha, D. V. (2014). The development of a scientometric database for monitoring the publication activities of Russian scientists at the Mendeleyev University of Chemical Technology of Russia. Scientific and Technical Information Processing, 40(4), 240-244. http://doi.org/10.3103/S0147688213040114 